\title{
ADOÇÕES, TRANSFERÊNCIAS FORÇADAS E GENOCÍDIO
}

\author{
ADOPTIONS, FORCED DISPLACEMENT AND GENOCIDE
}

Cássio Eduardo Zen*

\begin{abstract}
Resumo:
O artigo busca apresentar a transferência forçada de pessoas realizada por meio de processos aparentemente lícitos de adoções, como mecanismo de genocídio. Para tanto, o artigo irá além do mero texto legal do Estatuto de Roma, para se verificar casos históricos e situações que, mesmo com a aparência de programas oficiais de adoção, nada mais eram do que genocídios disfarçados de programas em favor de crianças. Apesar de a adoção ser um dos institutos mais nobres do direito, datando de tempos antigos, houve momentos e locais históricos nos quais a adoção forçada serviu para políticas estatais de higienização social, com efeitos que perduram.
\end{abstract}

Palavras-chave: Genocídio. Direito Criminal Internacional. Transferências Forçadas.

\begin{abstract}
:
The article seeks to present the forced displacement of persons through unlawful adoption processes, as a disguised genocide mechanism. In order to achieve that, the paper will go beyond the legal text of the Rome Statute to verify historical cases and situations that, even with the guise of official adoption programs, were nothing more than genocides disguised as child welfare. Although adoption being one of the noblest institutes of Law, dating back to ancient times, there were moments and historical times in which forced adoption served for state policies of social sanitation, with lasting effects.
\end{abstract}

Keywords: Genocide. International Criminal Law. Forced Displacements.

\section{Desafios da adoção internacional}

Segundo Diogo de Leite Campos (2008, p. 24), “adopção é um vínculo de parentesco legal", vínculo este irrevogável e estabelecido por sentença judicial, após processo no qual a criança deverá ser ouvida e o adolescente deverá expor sua concordância, segundo determinado no ordenamento jurídico brasileiro. A adoção é instituto de considerável nobreza, retirando crianças e adolescentes que por vezes encontram-se em situação indigna em instituições sem condições e estabelece vínculo de filiação fundado no afeto.

Toda adoção, invariavelmente, deverá ser realizada tendo em vista o melhor interesse da criança. Heloisa Helena Barboza (2000, p. 208) considera consolidado tal

Doutor em Direito Internacional pela Universidade de São Paulo. Professor universitário e advogado. 
princípio, tendo em vista as crianças e adolescentes como pessoas em desenvolvimento. Este princípio rege tanto as adoções nacionais quanto as adoções internacionais e, ainda assim, mesmo que alguns países ofereçam melhores condições de vida que o país de origem da criança ou adolescente, isto não significa que está no melhor interesse da criança ou adolescente a adoção internacional. A própria Convenção de Adoção da Haia afirma que adoções envolvendo países diferentes deverá ser feita tendo em vista os melhores interesses da criança e prevenir abdução, venda e tráfico. ${ }^{1}$

A adoção internacional, por expressa disposição convencional, somente será utilizada quando não for possível a adoção nacional. ${ }^{2} \mathrm{O}$ consentimento das pessoas, instituições e autoridades também é outro requisito previsto no caso de adoções internacionais, devendo ser escrito, livre, informado e anterior ao nascimento da criança. ${ }^{3}$ Exclui-se, por óbvio, situações nas quais após processo judicial contraditório, formal e legal, os pais da criança foram destituídos do poder parental (por exemplo, diante de um abuso contra o adolescente ou criança), quando não será exigido consentimento parental.

Elizabeth Bartholet expõe que, no caso das adoções entre pessoas situadas em países diferentes, as diferenças vão além da biológica. Em suas palavras: "na adoção internacional, pais adotivos e crianças se encontram através de linhas de diferença não envolvendo somente biologia, mas também classe socioeconômica, raça, etnia e herança cultural e nacionalidade". ${ }^{4}$ Há, assim, inúmeros desafios adicionais diante de uma adoção com contornos internacionais, ou como provoca Nicole Bartner Graff (2000), seria possível “controlar o livre mercado de crianças?”, pois como explica Michele Goodwin:

sabedoria convencional e legislações anteriores definiam o melhor interesse da criança como central para todas as adoções, que funcionavam como um modelo de bem estar infantil para jovens abandonados, vítimas de abuso, negligenciados e órfãos. Serviços de adoção contemporâneos, todavia, se assemelham a mercados livres nos quais perfis estéticos de raça, textura de cabelo, cor dos olhos e outras variantes mercadológicas determinam o bem estar das crianças ou, ao menos, a sua probabilidade de colocação. ${ }^{5}$

1 CONVENTION ON THE PROTECTION OF CHILDREN AND CO-OPERATION IN RESPECT TO INTER-COUNTRY ADOPTION (1993, preamble).

2 CONVENTION ON THE PROTECTION OF CHILDREN AND CO-OPERATION IN RESPECT TO INTER-COUNTRY ADOPTION, art. 4 (b).

3 CONVENTION ON THE PROTECTION OF CHILDREN AND CO-OPERATION IN RESPECT TO INTER-COUNTRY ADOPTION, art. 4.2.

4 "in international adoption, adoptive parents and children meet across lines of difference involving not just biology, but also socioeconomic class, race, ethnic and cultural heritage, and nationality". Bartholet (2006, p. 63).

5 "Conventional wisdom and early legislation held the best interest of children at the center of all adoptions, 
Por mais que a realidade de Goodwin seja a estadunidense, não se trata de algo muito distante do Brasil no qual se veem anúncios de "adoção" de moça para ser babá para um casal evangélico (REIS, 2015) e eventos em shopping center no qual pessoas desfilavam em busca de adoção como se fossem mercadorias, com o apoio institucional de órgãos que deveriam, supostamente, zelar pelo melhor interesse da criança e adolescente. (LEMOS, 2019) A situação ganha mais destaque quando se trata de adoção internacional, na qual diferentes sistemas jurídicos convivem. A venda de crianças e adolescentes como mercadorias não configuraria, em si, genocídio (foco deste artigo), por conta de detalhes que serão vistos no próximo capítulo deste artigo. Todavia, se em meio a determinado processo de adoção houver algum objetivo, mesmo que secundário, de com a adoção eliminar o grupo, será genocídio.

Considerando que a adoção deva ser um ato baseado em amor e no bem-estar da criança, não se pode aceitar as situações definidas como alienação cultural (othering) realizadas por alguns parentes adotivos. Trata-se de um processo no qual se estigmatiza a cultura anterior da adotada, (KING, 2009, p. 461) alienando-a de parte fundamental de sua própria identidade (KING, 2009, p. 462) e gerando riscos psicológicos para a criança. (SANTS, 1964, p. 140). Portanto, durante o processo de adoção, desde o estágio de convivência, os adotantes deverão compreender as peculiaridades culturais do adotando, pois esta criança ou adolescente não são um quadro em branco, sem história alguma, sem cultura alguma. $\mathrm{O}$ processo deve ser encarado como um aprendizado mútuo e não como alguma forma de imposição de uma cultura sobre a outra.

Não se almeja neste artigo defender o fim do instituto da adoção, nem o da adoção internacional. Todavia, defende-se aqui que prudência é necessária para evitar que adoções, ainda que judiciais, formais e legais, sejam efetivamente utilizadas para culturalmente eliminar determinado grupo por maiorias com desejo de higienização social. A história é cheia de exemplos nos quais crianças foram retiradas do convívio de seus pais com pretextos (supostamente nobres e altruístas) "civilizatórios", catequizadores, violando não só o melhor interesse da criança, mas configurando genocídio.

\section{Genocídio, cultura e o Direito Criminal Internacional}

Por muito tempo, imperou no Direito Internacional a cultura da impunidade pela prática de genocídio, uma vez que tais crimes contavam com o apoio, quando não o

which functioned as a child welfare model for abandoned, abused, neglected and orphaned youth. Contemporary adoption services, however, resemble free markets where aesthetic profiles of race, hair texture, eye color and other market variables determine the welfare of children or, at least, their likelihood of placement". Goodwin (2006, p. 62-63). 
protagonismo de estados. (SCHABAS, 2009, p. 1). Todavia, o cenário que se tem hoje é o de reconhecimento do genocídio como crime internacional ${ }^{6}$ e o foco na prevenção, além da punição do genocídio. (UNITED NATIONS, 1948). A definição de 1948 é falha, por excluir da aplicação da Convenção de Genocídio os atos praticados para se eliminar grupos de natureza política, orientação sexual e identidade de gênero, erro este infelizmente repetido em 1998 nas negociações do Estatuto de Roma, que copiou a definição trazida em 1948.

Conforme o Estatuto de Roma, o genocídio é composto da mens rea, o elemento subjetivo do crime (englobando o dolo geral e o elemento subjetivo do tipo diverso do dolo) e diversos actus reus alternativos, consistindo em atos ${ }^{7}$ como a morte de membros do grupo, a imposição de medidas para evitar nascimentos no grupo, o dano sério (psicológico ou físico) nos membros do grupo, a imposição de condições de vida calculadas para extermínio (como ocorrido em guetos) e a transferência forçada de crianças de um grupo para outro. Interessa em especial para este artigo a última modalidade, ligada a transferência forçada de crianças.

Schabas observa que este ato "se refere por óbvio a transferência de crianças que resulta em sua perda de sua identidade original como grupo", 8 enquanto Claus Kreß considera que esta modalidade estaria no limiar próximo ao que seria genocídio cultural, embora se aproxime igualmente de genocídio biológico. (KREß, 2006, p. 484). Portanto, mais do que a questão identitária, há a real possibilidade que por meio da transferência forçada, se esteja diante de uma situação de miscigenação e assimilação forçadas para eliminar características que componham determinado grupo protegido pela convenção de genocídio.

Raphael Lemkin, antes mesmo de elaborar o conceito de genocídio na década de 1940, tratou de dois crimes separados na $5^{\text {a }}$ Conferência Internacional sobre a Unificação do Direito Penal, em 1933. Naquela ocasião, defendeu a criação de dois crimes: o de barbárie, relacionado a um "conjunto de ações opressoras e destrutivas dirigidas contra indivíduos como membros de um grupo nacional, religioso ou racial" e o crime de vandalismo, que consistiria na "destruição maligna de obras de arte e de cultura sob o pretexto que representam as criações específicas do gênio de tais grupos". ${ }^{10}$

ROME STATUTE, 2002, art. 6.

ROME STATUTE, 2002, art. 6.

"obviously refers to the transfer of children that result in a loss of their original identity as a group". Schabas (2015, p. 140).

9 “ensemble d'actions opprimantes et destructrices dirigées contre des individus en tant que membres d'un groupe national, religieux ou racial". Lemkin (1933).

10 "destruction malveillante d'œuvres d'art et de culture sous prétexte qu'elles représentent les créations spécifiques du génie de tels groupes”. Lemkin (1933). 
Reforçando ainda a possibilidade da criminalização de um genocídio cultural, Lemkin afirmou, enquanto Hitler ainda aterrorizava a Europa, que o genocídio também poderia incluir "várias medidas engenhosas para enfraquecer ou destruir elementos políticos, sociais ou culturais em grupos nacionais", ${ }_{11}^{11}$ embora reconheça que estes atos não estariam proibidos pelas regulações da Haia. (LEMKIN, Raphael, 1944, p. 92). O conceito de genocídio, tanto na Convenção de 1948 quanto no Estatuto de Roma não aderiram integralmente a estes conceitos de Lemkin, focando na barbárie e não no vandalismo.

Não era este o propósito de Lemkin, que acreditava que a barbárie e o vandalismo seriam duas etapas de um mesmo processo. (LEMKIN, Raphael, 1944, p. 79). Em suas memórias, Lemkin afirmou que foi com coração pesado que desistiu da ideia durante a convenção, quando diante da falta de suporte teve que abandonar a ideia. (LEMKIN; FRIEZE, 2013, p. 173). Na opinião do jurista, apesar da derrota diplomática, foi possível a adoção de elementos do genocídio cultural, por exemplo no sequestro de crianças. (LEMKIN; FRIEZE, 2013, p. 173). Não é um grande salto, assim, afirmar que desde antes mesmo dos travaux préparatoires, a noção de genocídio cultural esteve umbilicalmente ligada ao tratamento que era dado às crianças de determinado grupo protegido.

A cultura é algo com múltipla dimensões. Como explica Paulo Borba Casella (2008, p. 493, grifo do autor), compõe-se de:

$$
\begin{aligned}
& \text { instituições, a saber as regras ou normas que governam o } \\
& \text { comportamento; idéias, conhecimento e convicções, nas } \\
& \text { várias dimensões, nas quais se manifestem (filosóficos, } \\
& \text { científicos, tecnológicos, históricos, sociológicos, etc.); e } \\
& \text { produtos ou artefatos materiais que os homens produzem e } \\
& \text { usam no curso de sua existência coletiva. }
\end{aligned}
$$

Além do aspecto material, o crime de genocídio se diferencia por conta de seu elemento subjetivo do tipo diverso do dolo, qual seja o dolus specialis consistindo na intenção de eliminar determinado grupo religioso, racial, nacional ou étnico, no todo ou em parte. Trata-se de um complemento, um indicativo do telos do ato de genocídio, o objetivo não é meramente transferir determinadas pessoas, nem matar determinadas pessoas, mas por meio destes atos eliminar o grupo ao qual esta pessoa pertence. A Corte Internacional de Justiça, embora não seja uma corte criminal (e por esta razão destaca-se o perigo de tal corte trilhar questões de direito penal) considerou que tal requisito vai além

\footnotetext{
11 "various ingenious measures for weakening or destroying political, social and cultural elements in national groups". Lemkin (1944, p. 92).
} 
do propósito discriminatório, exigindo-se a intenção de destruir. (INTERNATIONAL COURT OF JUSTICE, 2007, § 187).

Seria a questão da transferência forçada de crianças uma questão de genocídio biológico ou cultural? A questão é polêmica pois apesar de como Schabas (2009, p. 202) explica o dispositivo ter surgido não da Comissão de Direito Internacional, mas do Secretariado, como ato de genocídio cultural, do outro lado a Comissão de Direito Internacional, focando nos trabalhos da Convenção de 1948, apresenta posicionamento diametralmente oposto, afirmando que:

Como foi demonstrado claramente pelos travaux
préparatoires para a Convenção, a destruição em questão
é a destruição material de um grupo seja por meios físicos
ou biológicos, não a destruição da identidade nacional,
linguística, religiosa, cultural ou outra identidade de um
grupo particular. O elemento nacional ou religioso e o
elemento racial ou étnico não são levadas em consideração
na definição da palavra 'destruição' que deve ser observada
somente em seu sentido material, seu sentido físico ou
biológico. É verdade que o draft de 1947 da Convenção
preparado pelo Secretário-Geral e o draft de 1948 preparado
pelo Comitê ad hoc sobre Genocídio continha dispositivos
sobre 'genocídio cultural' tratando de qualquer ato
deliberado cometido com a intenção de destruir a língua,
religião ou cultura de um povo, tal como proibindo o uso
da linguagem do grupo no dia a dia ou em escolas ou a
impressão e circulação de publicações na linguagem dos
grupos ou destruindo ou impedindo o uso de bibliotecas,
museus, escolas, monumentos históricos, locais de culto ou
outras instituições culturais e objetos do grupo. Todavia, o
texto da Convenção, como preparado pelo Sexto Comitê e
adotado pela Assembleia Geral não incluiu o conceito de
'genocídio cultural' contido nos dois drafts e simplesmente
listou atos que se enquadram nas categorias de genocídio
'físico' ou 'biológico'.

12 "As clearly shown by the preparatory work for the Convention, the destruction in question is the material destruction of a group either by physical or by biological means, not the destruction of the national, linguistic, religious, cultural or other identity of a particular group. The national or religious element and the racial or ethnic element are not taken into consideration in the definition of the word "destruction", which must be taken only in its material sense, its physical or biological sense. It is true that the $1947 \mathrm{draft}$ Convention prepared by the Secretary-General and the 1948 draft prepared by the ad hoc Committee on Genocide contained provisions on "cultural genocide" covering any deliberate act com-mitted with the intent to destroy the language, religion or culture of a group, such as prohibiting the use of the language of the group in daily intercourse or in schools or the printing and circulation of publications in the language of the group or destroying or preventing the use of libraries, museums, schools, historical monuments, places of worship or other cultural institutions and objects of the group. However, the text of the Convention, as prepared by the Sixth Committee and adopted by the General Assembly, did not include the concept of 
Enrico Mezzetti, tratando da transferência forçada, considera que neste caso se verifica a uma antecipação do limiar de punibilidade em respeito ao grau da ofensa a vida ou a incolumidade individual dos sujeitos singulares que pertencem ao grupo: significativamente, nesta modalidade do crime, não se tem uma lesão destes bens mas se para na incriminação da transferência forçada das crianças. ${ }^{13}$

Em outras palavras, para Mezzetti, não há, neste actus reus de genocídio, o perigo direto a vida e a integridade individual das pessoas. Considerando que o tipo fala em crianças, trata-se de uma miscigenação forçada pois, quando estas crianças atingirem a idade adulta e eventualmente passarem a se reproduzir, estarão inseridas em outro grupo (racial, nacional, étnico ou religioso) e deste modo, no longo prazo, o grupo original das crianças deixará de existir como si, pois terá sido forçado a se misturar com outros grupos. As instituições, ideias, produtos materiais daquele grupo, que compõem a cultura, serão destruídas.

Acredita-se que o caráter biológico, neste caso de genocídio, seja secundário. Isto porque caso o grupo original ainda exista, quando adultos talvez as pessoas possam retornar ao seu grupo social original, ou até mesmo que voluntariamente não se reproduzam em seu novo grupo. Se fosse apenas uma questão biológica, não haveria motivo para restringir a aplicação do tipo a crianças, no que Mezzetti (2006, p. 594) considera uma proteção insuficiente. A ideia de impedir nascimentos no seio do grupo já é tratada em outro dispositivo do art. $6^{\circ}$ do Estatuto, o que faz com que a questão das transferências forçadas indique mais um propósito de impedir o crescimento e desenvolvimento de uma criança em determinado grupo do que de impedir que determinadas características biológicas do grupo sejam perpetuadas. No mesmo sentido, Damien Short considera que “genocídio cultural é genocídio e de modo restrito, não necessita do adjetivo 'cultural' uma vez que simplesmente serve para descrever um método de genocídio". ${ }^{14}$

Não significa dizer que as ideias de Lemkin sobre vandalismo tenham sido aceitas como componente do genocídio pelo Estatuto de Roma. O que restou previsto no art. 6 (e) é um genocídio (no caso de transferência forçada de crianças) primordialmente cultural. A ideia do vandalismo também se faz presente nos crimes de guerra, com a

"cultural genocide" contained in the two drafts and simply listed acts which come within the category of "physical" or "biological" genocide". United Nations (1991, p. 102, para 4).

13 "in questo caso si assiste ad un'anticipazione della soglia di punibilità rispetto al grado di offesa alla vita o all'incolumità individuale dei singoli soggetti che appartengono al gruppo: significativamente, in questa modalità del crimine, no si ha una lesione di questi beni ma ci si arresta all'incriminazione del trasferimento forzato dei bambini”. Mezzetti (2006, p. 593).

14 "cultural genocide is genocide and strictly speaking does not need the 'cultural' descriptor since it simply serves to describe a method of genocide". Short (2010, p. 844). 
destruição de objetos culturais. Ao mesmo tempo, reconhecer a transferência forçada de crianças como actus reus de genocídio é criminalizar um ato que acaba por aniquilar determinada cultura em alguns indivíduos. O menino-lobo Mogli, da fábula de Rudyard Kipling (1910), nunca mais foi o mesmo depois de ser criado por lobos.

A miscigenação é saudável, quando ocorre de modo voluntário. A interação e o aprendizado cultural intercivilizacional, do mesmo modo, proporcionam o progresso e a tolerância entre diferentes grupos. Vale aí a noção de Yasuaki Onuma (2017, p. 47), para quem

se as pessoas não puderem se libertar de uma noção substantiva e exclusiva de civilização, as perspectivas a partir das quais as pessoas buscam enxergar os fenômenos transfronteiriços ou globais ou as ideias associadas com culturas, religiões ou civilizações tenderão a levá-las à conclusão negativa de um choque de civilizações.

Políticas segregacionistas, como o Apartheid, são inclusive crimes no Estatuto de Roma.

O problema essencial é quando a interação por meio da transferência forçada de uma população para o seio de outra ocorre com o propósito genocida de eliminar o grupo. Sem este propósito, não ocorre genocídio. Foi com esta finalidade que diferentes programas ocorreram para arrancar crianças de seus pais, para a criação em grupos sociais diversos.

3. Casos históricos de transferências forçadas em processos de adoção

3.1 O caso das Mother and Baby Homes no Reino Unido e Irlanda

O programa de adoções forçadas que ocorria nas Mother and Baby Homes (no Reino Unido e na Irlanda), instituições que contavam com as bênçãos de autoridades seculares e espirituais (no caso especialmente as autoridades católicas) chegou até mesmo a produções cinematográficas que concorreram ao Oscar (Philomena). No caso irlandês, 14 Mother and Baby Homes e 4 casas de condado estão sob investigação de comissão do governo $^{15}$ estabelecida pelo Statutory Instrument No. 57 de 2015, com os objetivos de:

I. Estabelecer as circunstâncias e acordos para a entrada de mulheres solteiras nessas instituições e vias de saída em sua partida dessas instituições, incluindo considerar a extensão de sua participação em decisões relevantes. II. Estabelecer as condições de vida e cuidados experimentados pelos residentes durante seu período de acomodação nessas

15 IRELAND. Mother and Baby Homes Commission of Investigation. List of Institutions under investigation. 
instituições, inclusive por referência à literatura sobre as condições de vida e os arranjos de cuidados experimentados por mães e crianças candidatas de modo mais geral no período; III. Examinar a mortalidade entre mães e crianças residentes nessas instituições (para determinar as causas gerais, circunstâncias e taxas de mortalidade) e a comparar à literatura sobre a mortalidade entre outros grupos de mulheres e crianças conforme relevante; IV. Investigar práticas e procedimentos post-mortem a respeito de mães e crianças que morreram enquanto residiam nestas instituições, incluindo relatórios de mortes, providências funerárias e transferências de corpos para instituições educacionais com o propósito de exames anatômicos; V. Estabelecer a extensão da conformidade com os padrões éticos e regulamentares relevantes do momento em que foram conduzidos, pela Comissão, testes sistêmicos de vacinas realizados em crianças residentes em uma ou mais dessas instituições durante o período relevante (incluindo, inter alia, testes de vacinas realizados utilizando vacinas produzidas por Burroughs Welcome em 1960/61, 1970 e 1973); VI. Examinar as providências para a entrada de crianças nessas instituições nas circunstâncias em que suas mães não eram também residentes no momento de sua entrada; VII. Para crianças que não permanecem sob os cuidados de seus pais, examinar o caminho de saída das instituições para estabelecerem-se padrões de referência ou relacionamentos relevantes com outras entidades, e em particular identificar (a) medida em que o bem-estar e proteção da criança foram considerados em práticas relacionadas às suas colocações na Irlanda ou no exterior; (b) a extensão da participação das mães em decisões relevantes, incluindo (i) os procedimentos em vigor para obter consentimento das mães a respeito da adoção, e (ii) se esses procedimentos eram adequados na finalidade de garantir que esse consentimento fosse completo, livre e informado e (c) as práticas e procedimentos para colocação de crianças onde houve cooperação com outra pessoa ou pessoas no arranjo dessa colocação, isso para incluir onde uma organização intermediária acordou uma colocação subsequente; VIII. Identificar no contexto de exames específicos em (I) a (VII) acima, até que ponto qualquer grupo de residentes pode ter sido tratado sistematicamente de maneira diferente por qualquer motivo [religião, raça, identidade do viajante ou deficiência]; IX. A Comissão não deve procurar fornecer um relato de qualquer caso individual de modo a intervir 
em qualquer esforço por qualquer indivíduo para determinar sua identidade ou rastrear parentes de nascimento. ${ }^{16}$

Eoin O’Sullivan e Ian O’Donnel descrevem diferentes estabelecimentos na Irlanda com propósitos similares. As Reformatory Schools (depois reclassificadas como Industrial Schools) tinham o propósito de lidar com adolescentes em conflito com a lei, nos hábitos da indústria e na maioria administradas pela Igreja Católica e com recursos públicos. (O’SULLIVAN; O’DONNEL, 2007, p. 35-37). As County Homes, focadas em idosos, doentes, crianças e mães solteiras, epiléticos e "defeituosos mentais", ${ }^{17}$ que se transformaram em parte nas Mother and Baby Homes. (O'SULLIVAN; O'DONNEL, 2007, p. 39). Tratavam-se de organizações administradas por congregações religiosas femininas que focavam nas first offenders (rés primárias), assim denominadas as mulheres solteiras que dariam a luz fora do casamento e por isto precisariam permanecer nestas casas para evitar a reincidência, por serem consideradas "fracas de espírito". ${ }^{18}$ Como

16 I. To establish the circumstances and arrangements for the entry of single women into these institutions and the exit pathways on their leaving these institutions; this to include consideration of the extent of their participation in relevant decisions; II. To establish the living conditions and care arrangements experienced by residents during their period of accommodation in these institutions, including by reference to the literature on the living conditions and care experienced by mothers and children applying more generally during the period; III. To examine mortality amongst mothers and children residing in these institutions (to determine the general causes, circumstances, and rates of mortality) and to compare it to the literature on mortality amongst such other groups of women and children as might be relevant; To investigate post-mortem practices and procedures in respect of children or mothers who died while resident in these institutions, including the reporting of deaths, burial arrangements and transfer of remains to educational institutions for the purpose of anatomical examination; V. To establish the extent of compliance with relevant regulatory and ethical standards of the time of systemic vaccine trials found by the Commission to have been conducted on children resident in one or more of these institutions during the relevant period (including, inter alia, vaccine trials conducted using vaccines manufactured by Burroughs Welcome in 1960/61, 1970 or 1973); VI. To examine arrangements for the entry of children into these institutions in circumstances when their mother was not also resident at the time of their entry; VII. For children who did not remain in the care of their parents, to examine exit pathways on leaving these institutions so as to establish patterns of referral or relevant relationships with other entities, and in particular to identify(a) the extent to which the child's welfare and protection were considered in practices relating to their placement in Ireland or abroad; (b) the extent of participation of mothers in relevant decisions, including (i) the procedures that were in place to obtain consent from mothers in respect of adoption, and (ii) whether these procedures were adequate for the purpose of ensuring such consent was full, free and informed; and (c) the practices and procedures for placement of children where there was cooperation with another person or persons in arranging this placement, this to include where an intermediary organisation arranged a subsequent placement; VIII. To identify, in the context of the specific examinations at (I) to (VII)above the extent to which any group of residents may have systematically been treated differently on any grounds [religion, race, traveller identity or disability]; IX. The Commission shall not seek to provide an account of any individual case in such manner as to intervene in any effort by any individual to resolve their identity or trace a birth relative". (IRELAND, 2015, p. 3-4).

17 "mentally deffective". Observa-se ainda que o termo usado no artigo de O'Sullivan e O'Donnel (2007, p. 38), presente em documentos da época é "mentally deffective", sendo que em documentos da época se diferenciava entre "mentally deffective" e "mental disorder".

18 “weak willed". O’Sullivan e O’Donnel (2007, p. 39). 
coloca Paul Michael Garrett, "ser enviada para uma Mother and Baby Home trazia sérias desvantagens para mulheres, pois é cristalino que estas instituições foram feitas para servir a interesses masculinos e reforçar o poder e as vantagens sociais dos homens". ${ }^{19}$

O uso da expressão ré, normalmente adotado para questões de direito criminal, não é aleatório. Verificando a história destas instituições, Garrett expõe como se consideravam as mães solteiras em duas categorias: aquelas que poderiam ser recuperadas (first offenders) e aquelas sem esperança (less hopeful cases), reincidentes, que poderiam permanecer sob a custódia das Mother and Baby Homes enquanto assim determinado pela madre superiora da instituição, para que adquirissem moral. (GARRETT, 2017, p. 4). Cecil Barrett, defensor da postura católica nas adoções, defendia que sem a cura espiritual, seria inútil a assistência material às mães (BARRETT, 1952, p. 24), mostrando que os programas nestas instituições não foram realizados no melhor interesse das crianças, nem menos ainda em dar assistência às residentes.

Em uma das instituições investigadas, a Bon Secours Mother and Baby Home, administrada pelas irmãs de Bon Secours, centenas de corpos de crianças teriam sido encontrados (O'REILLY, 2014), motivando investigação do governo irlandês, que não concluiu o número exato de corpos e mortes. Além disso, o número de crianças traficadas para os Estados Unidos pode ultrapassar mil, considerando números somente desta instituição. (FÁTHARTA, 2015). Segundo Barrett, a maioria das adoções era realizada para casais estadunidenses brancos e católicos e continha caráter racista, pois a Irlanda era escolhida por ser menor a chance de a criança possuir "sangue negro". ${ }^{20}$

Havia, ainda, a preocupação em diferentes instituições para evitar que a criança fosse criada por pais não católicos, especialmente se as mães fugissem da Irlanda e fossem para a Inglaterra (GARRETT, 2000, p. 338-339), ou ainda que houvesse uma "contaminação" da mãe irlandesa católica caso, em outro país, ela se relacionasse com negros ou judeus (GARRETT, 2000, p. 341). Havia, assim, claros contornos de segregação racial e religiosa na prática das Mother and Baby Homes na Irlanda. Todavia, por mais que os atos praticados nestas "casas" sejam horripilantes e se aproximem em análise preliminar de crimes contra a humanidade (extermínio, homicídio, escravidão, transferência forçada, violência sexual de gravidade, privação de liberdade severa e perseguição), ${ }^{21}$ não há indícios, no momento, de que tais atos eram feitos com o propósito (mens era) do genocídio de destruir um grupo.

\footnotetext{
19 "Being sent to a Mother and Baby Home had substantial disadvantages for women, as it is clear that these institutions were designed to serve male interests and reinforce the power and social advantages of men". Garrett (2017, p. 5).

20 "negro blood". Garrett (2000, p. 334).

21 ROME STATUTE, 2002, art. 7(1).
} 


\subsection{O caso da Hilfswerk für die Kinder der Landstrasse e das Verdingkinder - Suíça}

Na Suíça, sistemas abomináveis também foram colocados em prática com os programas Hilfswerk für die Kinder der Landstrasse (Trabalho de ajuda para as Crianças da Estrada Rural, operado pela fundação Pro Juventute) e Verdingkinder (sistema de Crianças sob contrato), com o objetivo declarado de "sedentarizar" crianças de famílias consideradas nômades. ${ }^{22}$ Véronique Mottier (2008, p. 265) expõe como políticas de eugenia estavam presentes em alguns cantões suíços antes e depois da segunda guerra mundial. Roswitha Dubach (2017, p. 191) menciona que nos anos 1930 milhares de pessoas foram esterilizadas no cantão de Zürich, com argumentos eugênicos em cerca de $30 \%$ das recomendações deste procedimento. Não se trata do único exemplo de políticas eugênicas na Europa no século passado (menciona-se o caso da Suécia, onde milhares de mulheres consideradas inadequadas foram esterilizadas, bem como o mais notório caso da Alemanha nazista e a Gesetz zur Verhütung erbkranken Nachwuchses de 1933).

O motivo explícito do programa Hilfswerk für die Kinder der Landstrasse era o de eliminar a "escória da vagabundagem"23 através de colocação e educação. A palavra utilizada em alemão é composta, sendo que a parte "Vagant" também é associada a povos viajantes. Assim, pode-se afirmar que o propósito desta política era o de eliminar os povos viajantes, como os yénish. O diretor do programa Kinder der Landstrasse foi, até 1959, Alfred Siegfried, que seguia o pensamento de Josef Jörger, eugenista suíço autor do livro Psychiatrische Familiengeschichte (histórias de família psiquiátricas). Considerado um livro essencial da doutrina eugenista, o livro contém considerações a respeito da denominada vagabundagem, a imoralidade e a fraqueza de caráter, considerados no livro traços hereditários (JÖRGER, 1919, p. 1). Inspirado pelas ideias de Jörger, Siegfried acreditava que a educação poderia ser utilizada para, na visão dele, remediar crianças yénish e poderiam ser usados métodos como a esterilização caso a educação não servisse (MOTTIER, 2008, p. 266), como foi também verificado em pesquisa por Gisela Hauss e Béatrice Ziegler (2008, p. 766). Também há relatos de violência sexual contra crianças no âmbito da Pro Juventute. (MOTTIER, 2008, p. 267).

A fundação Pro Juventute foi fundada em 1912, em reunião em Olten presidida por Ulrich Willie Jr, admirador e financiador de Hitler e com a presença de

\footnotetext{
22 É necessária uma ressalva quanto a terminologia adotada neste artigo. Conforme a Stifung Fahrende, fundação que defende os direitos de diferentes minorias viajantes, a maior parte das minorias se autoidentificam como Yénish, sendo por vezes retratados pela mídia como Roma, Sinti e Manouche e na cultura popular como ciganos. Em textos históricos, por sua vez, é possível localizar termos pejorativos como heimatlos (sem pátria) e vagabundos. Para este artigo usaremos os termos yénish e povos viajantes, destacando a diversidade presente dentro dos grupos.

23 "Vagantenübel". Leimgruber, Sablonier e Meier (1998, p. 26).
} 
Guiseppe Motta, conselheiro federal ${ }^{24}$ e por diversas vezes presidente da Confederação. Siegfried foi o responsável, dentro da fundação, pelo setor da Hilfswerk für die Kinder der Landstrasse, após a publicação por Siegfried de dois artigos jornalísticos em Zürich sobre famílias ticinesas yéniches, que ele considerava etnias transnacionais. ${ }^{25} \mathrm{O}$ diretor do programa iniciado em 1926 defendia ainda o isolamento das crianças e pais (HUONKER, 1987 , p. 88), sendo que mais de 600 crianças teriam sido transferidas como parte do programa. (HUONKER, 1987, p. 88). Após petição ao governo federal suíço em 25 de fevereiro de 1929, a fundação passou a receber significativos recursos oficiais ${ }^{26}$ e atuou em cooperação com autoridades cantonais, especialmente do Cantão de Grischun para colocação das crianças em seu programa de tutela. ${ }^{27}$

Huonker explica que era política do programa a redução de custos, buscando colocação em casas de camponeses e em instituições religiosas. ${ }^{28}$ A colocação nestas instituições e casas, onde as crianças sofriam humilhações (por exemplo, eram forçadas a engolir seu próprio vômito), castigos corporais e abusos sexuais, era feita em detrimento de sua educação. ${ }^{29}$ Além disso, ocorreram esterilizações com propósito de eugenia dentro do programa, como coloca Sara Galle. ${ }^{30}$

Nem sempre as crianças colocadas no programa Hilfswerk für die Kinder der Landstrasse eram adotadas formalmente. Quantidade considerável destas crianças era inserida no sistema de Verdingkinder, ${ }^{31}$ crianças sob contrato (verdadeiro eufemismo para escravidão) ou Pflegekinder (crianças colocadas). Marco Hüttenmoser e Kathrin Zatti (2010) afirmam que o número total de crianças neste tipo de programa somente no Cantão de Bern era de 12.810 crianças. Até o desenvolvimento de uma estrutura protetiva dos direitos da criança e do adolescente na Suíça em 1981, os sistemas permitiram que milhares de crianças e adolescentes encontrados na rua, retirados de núcleos familiares, ou órfãos, fossem colocados a serviço de famílias agrícolas suíças nos Alpes. Questionase, tendo em vista esta história real e sombria da Suíça, se Heidi (SPYRI, 1880), uma das

${ }_{24}$ HUONKER, Thomas. La persécution des Yéniches en Suisse: retrait systématique des enfants, internement, entraves au mariage et stérilisation forcée, p. 3.

25 HUONKER, Thomas. La persécution des Yéniches en Suisse: retrait systématique des enfants, internement, entraves au mariage et stérilisation forcée, p. 4.

26 HUONKER, Thomas. La persécution des Yéniches en Suisse: retrait systématique des enfants, internement, entraves au mariage et stérilisation forcée, p. 5.

27 PRO JUVENTUTE. Foire aux Questions. p. 3.

28 HUONKER, Thomas. La persécution des Yéniches en Suisse: retrait systématique des enfants, internement, entraves au mariage et stérilisation forcée, p. 7.

29 HUONKER, Thomas. La persécution des Yéniches en Suisse: retrait systématique des enfants, internement, entraves au mariage et stérilisation forcée, p. 7.

30 "Dass in Graubünden eugenisch motivierte Sterilisationen an ehemaligen Mündeln der Pro Juventute erfolgte, ist nicht erstaunlich". Galle (2016, p. 592).

31 HUONKER, Thomas. La persécution des Yéniches en Suisse: retrait systématique des enfants, internement, entraves au mariage et stérilisation forcée, p. 6. 
maiores ícones da literatura suíça, não teria sido na verdade uma representação de uma destas crianças.

Em 2014, projeto de lei de iniciativa popular com milhares de assinaturas expôs a questão das reparações devidas às crianças vítimas de tais programas. A Bundesgesetz über die Rehabilitierung administrativ versorgter Menschen entrou em vigor em $1^{\circ}$ de agosto de 2014 (SCHWEIZERISCHE EIDGENOSSENSCHAFT, 2014), com foco na reabilitação das crianças submetidas ao regime de contratos. Posteriormente tal lei foi revogada e adotou-se uma nova lei, a Bundesgesetz über die Aufarbeitung der fürsorgerischen Zwangsmassnahmen und Fremdplatzierungen vor 1981, com "o propósito de reconhecer e reparar a injustiça feita às vítimas de medidas de coerção para fins de assistência e de colocação extrafamiliar anteriores a 1981 na Suíça" ${ }^{32}$

No texto da lei, reconhece-se uma série de violações sofridas pelas crianças, incluindo esterilização, abusos sexuais, exploração de trabalho, adoções e uso de medicamentos sem consentimento. ${ }^{33}$ A lei entrou em vigor em 2017, mais de 100 anos depois que a Pro Juventute começou a atuar. Porém, a fundação continua agindo, mesmo que o seu programa Hilfswerk für die Kinder der Landstrasse tenha sido fechado em 1973, como o próprio endereço eletrônico da fundação narra, ${ }^{34}$ ainda que de modo bem asséptico.

Seria possível considerar as ações da Hilfswerk für die Kinder der Landstrasse um genocídio? A própria fundação Pro Juventute afirma que: "segundo o direito em vigor atualmente, o fato de retirar e reeducar sistematicamente crianças para assimilação de uma minoria é considerado genocídio cultural. Atualmente a Suíça reconhece os povos de viagem como uma minoria nacional". ${ }^{35}$ Todavia, há três observações que devem ser feitas em uma perspectiva mais técnica do que a realizada pela fundação. Em primeiro lugar, a fundação utilizou o termo genocídio cultural de modo diferente do teorizado por Lemkin (como exposto no capítulo 2 deste artigo), pois não se tratava de um programa de vandalismo. Em segundo lugar, a transferência de crianças para criação em outro grupo, com o propósito de eliminar determinado grupo por razões étnicas, configura genocídio. Em terceiro lugar, considerando que o programa foi cenário de esterilizações eugênicas, resta claro outro actus reus típico do genocídio, qual seja a

32 "Dieses Gesetz bezweckt die Anerkennung und Wiedergutmachung des Unrechts, das den Opfern von fürsorgerischen Zwangsmassnahmen und Fremdplatzierungen in der Schweiz vor 1981 zugefügt worden ist”. Schweizerische Eidgenossenschaft (2017, art. 1, p. 753).

33 Schweizerische Eidgenossenschaft (2017, art. 2 (d), p. 754).

34 PRO JUVENTUTE. Histoire de La Fondation.

35 "Selon le droit en vigueur actuellement, le fait d'enlever et de rééduquer systématiquement des enfants pour assimiler une minorité est considéré comme un génocide culturel. Aujourd'hui, la Suisse reconnaît les gens du voyage comme une minorité nationale". PRO JUVENTUTE. Foire aux Questions. p. 5. 
adoção de medidas para prevenir novos nascimentos no grupo. $\mathrm{O}$ adjetivo cultural, na afirmação da fundação, encontra-se sem propósito. O ocorrido foi, tecnicamente falando, genocídio, simplesmente.

\subsection{Os casos nas Américas}

A história brasileira é marcada pelo tratamento inaceitável conferido a minorias. Mal o país foi descoberto, buscou-se colonizá-lo, sem pedir licença para os habitantes que aqui já estavam antes de 1500. O papel da Igreja Católica e de suas diferentes ordens durante a colonização (ou a aniquilação étnica e cultural dos índios) foi essencial. Em um primeiro momento, adotou-se a chamada catequese salvacionista, postulando-se que era necessário salvar as almas dos nativos o mais rápido possível, pois o senhor estaria logo ali. (PAIVA, 2000, p. 3). O propósito declarado, neste primeiro momento, era o de salvar almas, não necessariamente eliminar o grupo indígena (mesmo que isto significasse o abandono de sua religião anterior e a adoção da fé católica). Para atingir a salvação, foi necessário incutir o medo nos indígenas a respeito de um castigo divino eventual PAIVA, 2000, p. 5, havendo participação dos missionários nos castigos aplicados pelo governo. (PAIVA, 2000, p. 6).

Em um segundo momento, passou-se a fase do catequismo legalista, segundo a qual era necessário retirar os índios da desordem (associada ao diabo) e colocálos na ordem (associada ao deus católico). (PAIVA, 2000, p. 6). Cartas compiladas por Serafim Leite narram como era necessário "tirar-lhes os feiticeiros, mantê-los em justiça entre si e para com os cristãos, fazê-los viver quietos sem se mudarem para outra parte, se não for para entre cristãos, tendo terras repartidas que lhes bastem, e com estes padres da Companhia para os doutrinarem". (LEITE, 1954, t. 2, p. 447).

Eliminar os feiticeiros era essencial para poder transformar a fé dos indígenas. Inventou-se a figura de Tupã (CASCUDO, 1972, p. 882), transformando o barulho do trovão em um equivalente ao deus católico, como uma primeira passagem da assimilação cultural. Transformaram Jurupari, a mais difundida divindade indígena, em um demônio (CASCUDO, 2002, p. 58), pois precisavam induzir o medo e a dicotomia na mentalidade dos indígenas e assim também retirar o poder dos pajés (PAIVA, 2000, p. 12). Fica clara a intenção de destruir as instituições já presentes entre os indígenas, como explica José Maria Paiva: "O saber do pajé reflete a desordem, função do diabo. O missionário restaura a ordem. A salvação se impõe, agora, destruindo o saber (indígena) que confronta 'o' saber (português) e rejeitando a organização social que confronta a organização cristã”. (PAIVA, 2000, p. 13).

Outro ataque a instituições indígenas ocorreu por meio do aldeamento, contando-se com força militar para forçar os indígenas a congregarem-se em aldeias 
e abandonarem um estilo de vida mais nômade. (PAIVA, 2000, p. 14-15). Forçar determinado grupo a confinar-se em determinados lugares, como parte de um processo que visava, como etapa final, eliminar suas instituições (religião) não é algo distante demais do genocídio operado séculos depois em guetos. Como explica Paiva (2000, p. 1819), “ou o índio migra para bem longe da costa ou, por não ter outra saída, se convence de que o português, afinal, é maior, e se põe sob a custódia do jesuíta". O aldeamento ainda contribuiu para o alastramento de doenças que eram desconhecidas pelas populações locais, contribuindo para o seu extermínio. ${ }^{36}$ Relata-se que durante a guerra dos bárbaros, entre portugueses e tapuias/cariris, o destino de muitos tapuias foi o confino em missões católicas. (WILL, 2004, p. 40).

Com o período pombalino, até a independência (1760-1822) os jesuítas não mais puderam atuar no Brasil, não havendo uma educação voltada aos indígenas. (RODRIGUES; DIAS; LIMA, 2017, p. 8). Já durante o período do Império, os índios eram considerados órfãos, podendo ser deixados sob tutela de juízes (BRASIL, 1875, art. $4^{\circ}$ ), tornando-os virtualmente incapazes. Ainda, estabeleceu-se programa de catequização e ensino em áreas indígenas, com o objetivo explícito de "pregar a Religião de Jesus Christo" (BRASIL, 1846, art. $1^{\circ}$, parágrafo $7^{\circ}$ ). O número de crianças matriculadas nas instituições (que recebiam recursos da coroa para cada criança matriculada) não atendia aos anseios das ordens religiosas, motivando outra racionalidade a partir de 1876, com verdadeiros sequestros de crianças para as ordens (AMOROSO, 1998, p. 10).

Aline Costa narra o caso de Alto Alegre: “esses missionários construíram um internato e exigiram o afastamento das crianças indígenas da comunidade, no intuito de iniciar o processo de evangelização e civilização, tendo recebido terras e recursos financeiros do governo para a manutenção da missão" (COSTA, 2016, p. 31), sendo gradualmente aumentada a violência para "assimilar", o que foi refletido na reação das comunidades indígenas (COSTA, 2016, p. 32). Importante notar que para Mércio Pereira Gomes (1977, p. 112), os atos de violência dos indígenas teriam sido estimulados em parte pela inveja da população local. Além disso, aponta-se que epidemia ocorrida no internato teria esquentado os ânimos, pois os pais estavam preocupados (COELHO, 2000, p. 11) sobre a situação na qual estariam seus filhos.

Elizabeth Coelho cita relatos de freis capuchinhos ligados a missão em Alto Alegre, narrando como meninos teriam sido "obtidos" (sic), alguns teriam "ido para o céu" e alguns aprenderam, enquanto os religiosos por pouco não foram flechados (COELHO, 2000 , p. 10). Baseada em relatos colhidos de famílias que foram afetadas por Alto Alegre, Coelho explica, ainda, que "o frade mandava prender aquele que resistisse à catequese

$\overline{36}$ Neste sentido vale o artigo de Carina dos Santos Almeida e Ana Lúcia Vulfe Nötzold (2008). 
e ao trabalho da lavoura, assim como mandava arrebanhar aqueles que se encontrassem escondidos pela mata" (COELHO, 2000, p. 8). Os índios tinham, deste modo uma falsa escolha entre a catequese ou a prisão, em meio a verdadeiro proselitismo coercitivo.

$\mathrm{O}$ internato era considerado como parte essencial da catequização, pois se acreditava que "para facilitar a cristianização dos índios, era melhor retirá-los do convívio com suas famílias" (COELHO, 2000, p. 9). Houve, deste modo, deslocamento forçado de crianças da etnia Tenetehara, as quais eram "obtidas" para serem separadas de seus pais e então submetidas a um internato, onde, como explica Mércio Gomes, a rotina era árdua, envolvendo acordar às 5 e meia da manhã, missa as seis, trabalho as sete, depois aulas, mais um turno de trabalho de tarde, indo dormir as oito da noite após orações (GOMES, 1977, p. 111). As crianças eram deslocadas de suas famílias e passavam pela vigilância constante, em ambiente estranho, similar a panóptica (COELHO, 2000, p. 9).

Sobre esta assimilação, Vanessa Anelise Rocha (2014, p. 4) explica que "coube aos religiosos o papel de expandir a fé católica, mas também fazer dos índios súditos cristãos", súditos estes colocados convenientemente em sistema equivalente ao de órfãos. Diferentes povos indígenas foram aniquilados ao longo da história brasileira. Como coloca Aryon Rodrigues (1986, p. 19)

em consequência das campanhas de extermínio ou de caça a escravos, movidas pelos europeus e por seus descendentes e prepostos, ou em virtude das epidemias de doenças contagiosas do Velho Mundo, deflagradas involuntariamente (em alguns casos voluntariamente) no seio de muitos povos indígenas; pela redução progressiva de seus territórios de coleta, caça e plantio e, portanto, de seus meios de subsistência, ou pela assimilação, forçada ou induzida, aos usos e costumes dos colonizadores.

No mesmo sentido, acompanha Carlos Eduardo Penha Everton (2016, p. 43):

Os prejuízos causados aos indígenas em todo território americano e, em nossa particularização, brasileiro e maranhense, são notórios e incontestáveis. Submissão a migrações compulsórias, extermínio de povos e culturas, marginalização social, são algumas faces da realidade a que essas populações foram (e ainda são) submetidas. Quanto mais aprofundavam a conquista desse espaço mais impactos os colonizadores provocavam sobre os índios.

Infelizmente, a exclusão de indígenas permanece, em especial por conta de conflitos de terra. As principais causas do genocídio indígena em nosso país foram a violência, as epidemias, mas também pode-se incluir nesta lista processos de assimilação forçada como o de Alto Alegre. Por mais que os colonizadores e as ordens 
religiosas quisessem "salvar a alma" dos indígenas e "civilizá-los", não foi perguntado se era necessária tal salvação (pois os indígenas sequer acreditavam em inferno) nem muito menos se o que os portugueses ofertavam (escravidão e exclusão social) poderia ser considerado "civilização". Os indígenas, por óbvio, não foram consultados sobre se desejavam tal "civilização" e tal "salvação". Desde 1500 Portugal, e depois Brasil, tiveram protagonismo em processo de aniquilação cultural e física de populações indígenas.

Nos Estados Unidos, onde em tempos recentes a Immigration and Customs Enforcement enjaulava crianças migrantes longe dos pais (SEPARATION, 2018) também há um passado sombrio. Um dos períodos mais graves das políticas para indígenas nos EUA ocorreu através do Indian Adoption Project e através das boarding schools (a partir de 1870). O Indian Adoption Project (IAP) operou entre fevereiro de 1959 até 1967 (PALMISTE, 2011, p. 1) e afetou oficialmente 395 (FANSHEL, 1972, p. 34) crianças, embora pesquisadores apontem para estimativas de mais de 12 mil crianças (PALMISTE, 2011, p. 5). Três organizações contribuíam em sua estrutura, o U.S. Census Bureau (a entidade do censo estadunidense, que dava suporte no planejamento do projeto), o Child Welfare League of America (CWLA, liga federal de associações de adoção, que administrava e conduzia o projeto) e o Bureau of Indian Affairs (BIA), que apoiava financeiramente o projeto. Claire Palmiste explica que "parentes nativos eram tidos como incapazes de cuidar de suas crianças e as oferecerem uma vida melhor". ${ }^{37}$ Em parte, isto era resultado de uma visão que considerava necessário "salvar" crianças da pobreza por meio da adoção.

Outra razão apontada para tal programa era o crescimento do tamanho das tribos. Com o aumento delas, o governo federal dos EUA era obrigado a alocar mais recursos para tais tribos. Como resultado "para cortar as despesas, reduzir os membros das tribos por meio de adoção parecia uma boa solução". (PALMISTE, 2011, p. 3). Trata-se, portanto, da transferência de crianças de um grupo para outro, com a finalidade de diminuir o tamanho do grupo, eliminando-o (no todo ou em parte). Outro fator que contribuiu para o aprofundamento do programa foi a impossibilidade de famílias nativas serem habilitadas para processos de adoção, por razões financeiras (PALMISTE, 2011, p. 3). Adoções seguiam a política do livre mercado, havendo tabelas para taxas que variavam conforme a renda das famílias e as crianças nativas eram vendidas como commodity a qual as famílias nativas eram consideradas inaptas para pagar.

Claire Palmiste considera que o programa de adoção consistia em genocídio cultural. Nas palavras da autora:

\footnotetext{
37 "native parents were regarded as incapable of taking care of their children and of offering them a better life". Palmiste (2011, p. 2).
} 
a adoção de crianças nativas por famílias brancas foi parte do processo de genocídio cultural. Isso significa para as tribos serem privadas de suas crianças, aquelas que poderiam passar adiante as tradições e permitir às tribos a se distinguirem da cultura mainstream. ${ }^{38}$

As violações realizadas pelo IAP foram investigadas pelo senado estadunidense entre 1974 e 1977, motivando o estabelecimento do Indian Child Welfare Act (HOLLINGER, 1988, p. 454). Esta lei permitiu um sistema que visa "proteger os melhores interesses da criança indígena e promover segurança, sobrevivência e estabilidade de famílias e tribos indígenas", ${ }^{39}$ mesmo que se admita que a questão de adoção de indígenas por famílias não indígenas seja controversa.

Porém, não foi este o único dos programas que deixou profundas marcas na população indígena dos EUA. Além do programa de adoções, foi aplicado nos Estados Unidos o programa das Indian Boarding School, operado tanto por agências federais (Federal Boarding Schools) quanto por entidades religiosas cristãs (Christian Boarding Schools). A escola modelo deste sistema, a Carlisle Indian Industrial School, na Pensilvânia tinha como propósito declarado "matar o indígena", ${ }^{40}$ ou seja, matar as características indígenas no estudante, e "salvar o homem", ${ }^{41}$ transformando o indígena em uma pessoa alheia a sua própria origem e um mero trabalhador braçal industrial.

Lindsay Glauner explica que "internatos para indígenas, incluindo Carlisle, usavam um 'sistema de distanciamento', que envolvia a transferência de uma criança na escola para a casa de uma família branca para doutrinar as crianças no estilo de vida estadunidense". ${ }^{42}$ Para garantir a cooperação das famílias indígenas neste programa, era juridicamente possível que o governo federal, por meio do BIA, parasse de fornecer os alimentos às famílias indígenas que não autorizassem o envio de suas crianças para tal sistema. (GLAUNER, 2002, p. 943).

Trata-se, portanto, de claro caso de transferência forçada, mediante ameaça da fome, relembrando que para a configuração do genocídio, o aspecto forçado da transferência não é restrito à violência física, podendo incluir grave ameaça de sofrimento

\footnotetext{
38 "The adoption of Native children by white families participated into the process of cultural genocide. It means for the tribes to be deprived of their children, the ones who could pass on the traditions and permit tribes to be distinct from the mainstream culture". Palmiste (2011, p. 4).

39 "to protect the best interests of Indian children and to promote the security, survival and stability of Indian families and tribes". Hollinger (1988, p. 452).

40 "kill the indian". Glauner (2002, p. 941).

41 "save the man". Glauner (2002, p. 941).

42 'Native American boarding schools, including Carlisle used an 'outing system,' which involved the transfer of a child from the school into the home of a white family to indoctrinate the children in the American way of life". Glauner (2002, p. 942).
} 
(INTERNATIONAL CRIMINAL COURT, 2011). Glauner detalha o inferno pelo qual estas crianças precisavam passar dentro da escola:

\begin{abstract}
Uma vez chegando no internato, as crianças não podiam mais falar com suas famílias, para que se acelerasse o processo de assimilação. Subsequentemente, estudantes que chorassem por saudade de casa frequentemente apanhavam, e aqueles que tentassem fugir eram acorrentados em cadeias improvisadas como punição. Todos estes atos, os espancamentos e as regulações, eram levadas a cabo com o propósito específico de assimilar a 'besta selvagem' para o estilo de vida do homem branco, para se destruir todas as coisas indígenas. ${ }^{43}$
\end{abstract}

O esquema das boarding schools (formas de internatos) foi encerrado oficialmente na década de 1970 com o Indian Child Welfare Act. Todavia, apesar de pedidos em 2000 de desculpas da BIA pelo seu papel em tais programas, não houve, até o encerramento deste artigo, o estabelecimento de comissão da verdade dos Estados Unidos, ou qualquer tipo de organismo similar, para buscar esclarecimentos a respeito do que ocorreu e a eventual reparação do sofrimento causado.

Ainda na América do Norte, outro país ainda está com dificuldades para enfrentar seu passado horrível. As autoridades canadenses participaram do Indian Resident School System, obrigando crianças nativas a serem "aculturadas" na cultura canadense predominante. David MacDonald e Graham Hudson consideram que boa parte dos desafios dos povos aborígenes no Canadá derive da atuação destas escolas. (MACDONALD, 2012, p. 428). O primeiro momento de escolas deste modelo no Canadá data de 1620 , com escolas fundadas pelos frades récollets (unificados em $1897 \mathrm{com}$ os franciscanos) e pelas freiras ursulines, tendo sido estabelecido um modelo de escolas após estudo feito por Egerton Ryerson em 1847. (TIMELINE, 2008). O Act Respecting Indians, de 1876, que regulamentava a questão indígena, foi emendado em $1884,{ }^{44}$ tornando obrigatória a frequência nestas escolas até os 16 anos. Com base nesta autorização legal, crianças eram retiradas de suas famílias para serem educadas em escolas para indígenas e, dos 16 até os 18 anos, em Industrial Schools. Jim Miller define tais escolas como "uma tentativa de tanto educar quanto converter jovens indígenas e os integrar na sociedade canadense, os

\footnotetext{
43 "Upon arrival at the boarding school, the children were not allowed to speak to their families in order to accelerate the assimilation process. Subsequently, students who cried from homesickness were often beaten, and those who attempted to run away were often chained in makeshift jails as punishment. All of these acts, the beatings and the regulations, were carried out with the specific purpose of assimilating the 'savage beast' to the white man's way of life in order to destroy all things Indian”. Glauner (2002, p. 943).

44 CANADA. Indian Act, 43V c.28, s.1, section 138, 2.
} 
internatos perturbando vidas e comunidades e causando problemas a longo prazo entre povos indígenas". 45

Dados estatísticos revelam que o percentual das crianças de etnias indígenas nas escolas era de quase cinco vezes o número de crianças de outros grupos (CANADA, 2015 b, p. 147), sendo que os pais das crianças sequer precisavam ser comunicados da ordem de envio das crianças para os internatos. (CANADA, 2015b, p. 147). Estes eram locais que não contavam com a estrutura necessária para serem instituições de acolhimento de crianças e adolescentes (CANADA, 2015b, p. 148-149) e "desencorajavam visitas". ${ }^{6}$ Deste modo, as escolas acabaram por impedir a transmissão de saberes e tradições indígenas para a criança, no que a Truth and Reconciliation Commission (TRC) denominou de política canadense de genocídio cultural. (CANADA, 2015a, p. vii).

A última das escolas desta categoria, a Gordon's Residential School, ${ }^{47} \mathrm{em}$ Punnichy, Saskatchewan, foi fechada somente em 1996. (MILLER, 2012). Em 2006, uma class action foi movida pelas First Nations obteve-se um acordo judicial, o maior da história canadense. Como parte do acordo, estabeleceu-se a TRC, para expor esta história sombria do Canadá. Esta comissão da verdade e reconciliação apresentou seu relatório final em 2015, com seis volumes (o volume 1 é dividido em 2 livros). Através do estudo destes documentos, é possível se ter uma visão histórica e jurídica a respeito dos eventos que ocorreram e afetaram 150 mil pessoas de etnias indígenas. (CANADA, 2015a, p. viii).

$\mathrm{O}$ assunto das populações nativas do Canadá ainda causa forte comoção no país. Como disse Murray Sinclair (chefe da TRC), trata-se de um dos capítulos mais perturbadores da história canadense. (CANADA, 2015a, p. vii). Também se trata de assunto atual, pois o Primeiro-Ministro Justin Trudeau viajou em 8 de março de 2019 para comunidades inuit para se desculpar em nome da Coroa pelo tratamento dado pelo governo federal canadense a população inuit durante surto de tuberculose na região nas décadas 1940 até meados da década de 1960. Durante este período o governo canadense teria separado famílias sem o consentimento (e sem informar aos parentes) e enviado pacientes para tratamento na região Sul do Canadá, com o propósito colonial. (SHARP, 2019).

Damien Short (2010, p. 839) aponta para a similaridade de experiências vividas em diferentes locais na América do Sul, América do Norte, África e Oceania, envolvendo condições de vida inaceitáveis, sendo identificadas pelos povos como

\footnotetext{
45 "an attempt to both educate and convert Indigenous youth and to integrate them into Canadian society, residential schools disrupted lives and communities, causing long-term problems among Indigenous peoples". (MILLER, 2012).

46 "discouraged visits". (CANADA, 2015b, p. 156).

47 Os relatos e sobre esta instituição chocam. Relatos variam desde abuso sexual, maus tratos, experimentos médicos e mortes de internos. (CANADA, 2015b, p. 230, 387 e 445; NIESSEN, 2017, p. 64-65).
} 
genocídio. Casos também foram identificados na Europa, indicando que se trata de uma prática comum em diferentes locais do globo. Casos como o da Suíça, Irlanda e Canadá envolveram alguma forma de comissão da verdade, para averiguar violações feitas a etnias no passado. O Brasil ainda está muito atrás, tanto no reconhecimento de tais violações do passado quanto em alguma tentativa de reparação.

\section{Conclusões}

Como coloca Goodwin, a adoção não é mais um assunto local, mas um verdadeiro "serviço multimilionário transnacional onde estética e traços genéticos são significativamente examinados". ${ }^{48}$ Onde há muito dinheiro envolvido, há a possibilidade que pessoas com interesses escusos acabem distorcendo procedimentos para obter lucros ilícitos e imorais. Além disso, onde há a possibilidade de juridicamente se retirar crianças e adolescentes de seus pais (mesmo que em diversos casos, reconheça-se, seja necessário para atender o melhor interesse da criança) e criar tais crianças em outro grupo (o que só pode ocorrer em último caso e atendendo os princípios fundamentais do direito da criança e do adolescente), surge a possibilidade que isto seja utilizado para a prática de genocídio.

Vítimas deste tipo de política estatal são, como admitido na Irlanda (LEO, 2018), na Austrália 2013 e no Canadá (CANADA, 2008; BUNCOMBRE, 2018), vítimas. Longe de atingir o melhor interesse das crianças e adolescentes, as adoções forçadas sem respeitar os ditames legais e muito menos o melhor interesse da criança, acabam por configurar práticas odiosas, por vezes com traços típicos de genocídio. Isto deve servir de alerta para que seja adotada cautela adicional durante processos de adoção de crianças de minorias ou migrantes para que se preserve o seu melhor interesse.

O Brasil adotou interessante saída para a questão de crianças e adolescentes indígenas ou quilombolas, dando a preferência pela adoção feita no âmbito de seus grupos sociais, bem como deve ser verificado o respeito às tradições e cultura da criança ou adolescente adotada e a oitiva de órgãos federais e especialistas. Isto é um desdobramento do princípio do melhor interesse da criança, que deve ser sempre o norte em todas as adoções.

Foram verificadas algumas características comuns nos programas da Irlanda, Reino Unido, Suíça, Brasil, Estados Unidos e Canadá. A primeira característica comum foi o desrespeito a alteridade. O "outro", a "minoria" (seja ela um povo nômade, seja ela um povo indígena) acabava sendo menosprezada por suas características e a única saída na visão da maioria seria transformar a minoria em uma parte da maioria, aniquilando se

\footnotetext{
48 "multi-million dollar transnational service where aesthetics and genetic traits are significantly scrutinized". Goodwin (2006, p. 73).
} 
fosse necessário suas características peculiares. Ao invés de aprender com as diferenças, buscou-se aniquilá-las.

A segunda característica é a suposta crença em um aspecto quase messiânico de tais projetos. Imbuídos de um espírito supostamente cristão (mas ignorando a simples fundamental lição de amar o próximo), organizadores de tais programas afirmavam que era necessário salvar as crianças. Pergunta-se: salvá-las do que exatamente? De suas próprias famílias? Por que razão estas crianças precisariam ser salvas de suas próprias famílias? Por serem estas famílias diferentes da maioria (e aí remete-se a primeira característica comum identificada)? Afirmar que determinado projeto nada mais é que um genocídio cultural não é algo bom para a imagem. Por esta razão, distorce-se a realidade e afirma-se que são programas de amparo a crianças.

A terceira característica é a relação econômica que se construiu. $O$ processo "civilizador" empreendido nestes projetos tinha também o propósito de preparar populações consideradas "vagabundas" para o mercado do trabalho, em escolas industriais e em fazendas. Não havia o propósito de instrução qualificada, a educação era para o trabalho menos qualificado e pior pago. Isto ganha contornos alarmantes com a real possibilidade de mercantilização de processos de adoção.

A quarta característica foi o desrespeito frequente ao melhor interesse da criança. Nos diversos projetos estudados, verificou-se que as crianças eram vítimas de toda forma de abuso. Apesar de o foco deste artigo ter sido o crime de genocídio por meio da transferência forçada, há indícios de diversos crimes internacionais que podem ter acontecido dentro destes programas.

A quinta característica identificada foi a existência de amparo jurídico para os projetos, com apoio oficial. Não é por conta da existência de uma lei que o adolescente ou a criança estarão protegidos. Não é porque determinado projeto conta com o amparo de instituições religiosas ou de entes estatais que será respeitado o princípio do melhor interesse. $\mathrm{O}$ estado e instituições religiosas acabam, por vezes, se envolvendo em condutas ilícitas. Como resultado, não se pode ater meramente nos aspectos legalistas das adoções internacionais e das transferências de crianças, pois em muitos aspectos operações em conformidade com a lei contrariam os princípios jurídicos.

Provavelmente, caso esta pesquisa fosse expandida para outros países, seriam localizadas outras situações similares (só não se expandiu porque ultrapassaria os propósitos de um artigo). Infelizmente, acredita-se que tenha sido ultrapassado o tamanho esperado de um artigo. Isto não significa que a gravidade do ocorrido nas situações aqui tratadas seja maior do que a ocorrida em outros lugares. Sabe-se, por exemplo, que o tratamento dado a aborígenes na Austrália contém casos de transferência forçada e outras violações grotescas de direitos humanos, no que ficou chamado do caso das Stolen Generations (ou Stolen Children). Do mesmo modo, notícias atuais preocupantes indicam 
a matrícula forçada de crianças no Paquistão em escolas madrassas (ABDOURAHIM; SIDDIQUI, 2014) e a abertura de diferentes campos na China, na região autônoma de Xinjiang (新疆) para a "reeducação" da minoria uighur. (INSIDE, 2019).

Não se trata de criticar determinada(s) religião(ões) ou estado(s). O problema essencial que se quis levantar neste artigo foi a coerção para a transferência de pessoas, para qualquer instituição ou família de outro grupo social. Os resultados destas transferências forçadas são devastadores para as crianças, os parentes e comunidades afetadas. Apesar de o genocídio cultural ser matéria controversa no direito criminal internacional, isto não impede que, durante procedimentos de adoção internacional, os operadores do direito verifiquem, tendo em vista o melhor interesse da criança, como preservar os vínculos e traços culturais peculiares da adotanda.

São Paulo, junho de 2019.

\section{Referências}

ABDOURAHIM, Kamal; SIDDIQUI, Taha. Pakistani parents forced to send children to madrassas. FRANCE24, 7 July 2014. Disponível em: https:/www.france24.com/en/focus/20140707-2014-0707-0746-focus.

ALMEIDA, Carina Santos de; NÖTZOLD, Ana Lúcia Vulfe. O impacto da colonização e imigração no Brasil meridional: contágios, doenças e ecologia humana dos povos indígenas. Tempos Acadêmicos: Revista do Curso de História, Criciúma, n. 6, 2008.

AMOROSO, Marta Rosa. Mudança de hábito: catequese e educação para índios nos aldeamentos capuchinhos. Revista Brasileira de Ciências Sociais, São Paulo, v. 13, n. 37, jun. 1998.

AUSTRALIA. Attorney General's Department. National apology for forced adoptions. Canberra, Mar. 2013. Disponível em: https://www.ag.gov.au/About/ForcedAdoptionsApology/Pages/default. aspx.

BARBOZA, Heloisa Helena. O princípio do melhor interesse da criança e do adolescente. In: CONGRESSO BRASILEIRO DE DIREITO DE FAMÍLIA, 2., 1999, Belo Horizonte. PEREIRA, Rodrigo da Cunha (coord.). A família na travessia do milênio. Belo Horizonte: IBDFAM, 2000. p. 201-213.

BARRETT, Cecil Jeremiah. Adoption: the parent, the child, the home. Dublin: Clonmore \& Reynolds, 1952.

BARTHOLET, Elizabeth. International adoption. In: ASKELAND, Lori. Children and youth in adoption, orphanages and foster care: a historical handbook and guide. Westport: Greenwood, 2006. p. 63-78. 
BRASIL. Decreto n. 426, de 24 de julho de 1845. Contém o Regulamento ácerca das Missões de catechese, e civilisação dos Indios. BRASIL. Collecção das Leis do Império do Brasil de 1845. Rio de Janeiro: Typographia Nacional, 1846. t. 8, parte 2. p. 86-96. Disponível em: http://bd.camara.gov. br/bd/bitstream/handle/bdcamara/18344/colleccao_leis_1845_parte2.pdf?sequence=2.

BRASIL. Lei de 27 de outubro de 1831. Revoga as Cartas Régias que mandaram fazer guerra, e pôr em servidão os índios. BRASIL. Collecção das Leis do Império do Brasil de 1831. Primeira Parte. Rio de Janeiro: Typographia Nacional, 1875. p. 165-167. Disponível em: http://bd.camara.gov.br/ bd/bitstream/handle/bdcamara/18460/colleccao_leis_1831_parte1.pdf?sequence=3.

BUNCOMBE, Andrew. Where is my baby? How Canada confronted the scandal of forced adoption. Independent, London, 26 Oct. 2018. Disponível em: https://www.independent.co.uk/news/long reads/canada-forced-adoption-scandal-baby-justin-trudeau-children-mothers-apologise-a8535061. html.

CAMPOS, Diogo Leite de. Lições de direito da família e das sucessões. 2. ed., rev. e actualizada. Coimbra: Almedina, 2008.

CANADA. Indian Act, 43V c. 28, s. 1, 1884. Revised Statutes of Canada.

CANADA. Indigenous and Northern Affairs. Statement of apology to former students of Indian Residential Schools. 11 June 2008. Disponível em: https://www.aadnc-aandc.gc.ca/DAM/DAMINTER-HQ/STAGING/texte-text/rqpi_apo_pdf_1322167347706_eng.pdf.

CANADA. Truth and Reconciliation Commission. Canada's residential schools: the history, part 1: origins to 1939. Toronto: McGill-Queen's University Press, 2015a. (The Final Report of the Truth and Reconciliation Commission of Canada, v. 1). Disponível em: http:/nctr.ca/assets/reports/ Final\%20Reports/Volume_1_History_Part_1_English_Web.pdf.

CANADA. Truth and Reconciliation Commission. Canada's residential schools: the history, part 2: 1939 to 2000. Toronto: McGill-Queen's University Press, 2015b. (The Final Report of the Truth and Reconciliation Commission of Canada, v. 1). Disponível em: http://nctr.ca/assets/reports/Final\%20 Reports/Volume_1_History_Part_2_English_Web.pdf.

CASCUDO, Luís da Câmara. Dicionário do folclore brasileiro. Rio de Janeiro: Ministério da Educação e Cultura, Instituto Nacional do Livro, 1972.

CASCUDO, Luís da Câmara. Geografia dos mitos brasileiros. 2. ed. São Paulo: Global, 2002.

CASELLA, Paulo Borba. Fundamentos do direito internacional pós-moderno. São Paulo: Quartier Latin, 2008.

COELHO, Elizabeth Maria Beserra. Catequização e conquista: a missão capuchinha entre os Tenetehara no Maranhão. In: REUNIÃO BRASILEIRA DE ANTROPOLOGIA, 22., 2000, Brasília. Anais [...]. Brasília: Associação Brasileira de Antropologia, Universidade de Brasília, 2000. 
CONVENTION ON THE PROTECTION OF CHILDREN AND CO-OPERATION IN RESPECT TO INTER-COUNTRY ADOPTION, Den Haag, 1993. Disponível em: https://assets.hcch.net/ docs/77e12f23-d3dc-4851-8f0b-050f71a16947.pdf.

COSTA, Aline Guedes da. "Crianças adotadas": um estudo sobre o direito humano a ter um povo. 2016. Brasília: Dissertação (Mestrado em Direitos Humanos e Cidadania) - Universidade de Brasília, Brasília, 2016.

DUBACH, Roswitha. Zur 'Sozialisierung' einer medizinischen Massnahme: Sterilisationspraxis der Psychiatrischen Poliklinik Zürich in den 1930er Jahren. In: MEIER, Marietta; GERMANN, Urs; BERNET, Brigitta; DUBACH, Roswitha. Zwang zur ordnung: psychiatrie im Kanton Zürich, 1870-1970. Zürich: Cronos, 2007. p. 155-192.

EVERTON, Carlos Eduardo Penha. "Hoje e amanhã celebrai a história para encarnar-vos no Povo": os embates de memória sobre o Conflito de Alto Alegre. Dissertação (Mestrado em História, Ensino e Narrativas) - Universidade Estadual do Maranhão, São Luís, 2016.

FANSHEL, David. Far from the reservation. New York: Scarecrow, 1972.

FÁTHARTA, Conall Ó. Special investigation. Fears over 'trafficking' of children to the US. Irish Examiner, Dublin, 3 June 2015. Disponível em: https://www.irishexaminer.com/ireland/specialinvestigation-fears-over-trafficking-of-children-to-the-us-334315.html.

GALLE, Sara. Kindswegnahmen: das "hilfswerk für die kinder der landstrasse" der stiftung Pro Juventute im kontext der schweizerischen jugendsfürsorge. Zürich: Chronos, 2016.

GARRETT, Paul Michael. Excavating the past: mother and baby homes in the Republic of Ireland. British Journal of Social Work, Oxford, v. 47, n. 2, p. 358-374, March 2017.

GARRETT, Paul Michael. The abnormal flight: the migration and repatriation of Irish unmarried mothers. Social History, London, v. 25, n. 3, p. 330-343, Oct. 2000.

GLAUNER, Lindsay. The need for accountability and reparations: 1830-1976 and the United States government's role in the promotion, implementation and execution of the crime of genocide against native Americans. DePaul Law Review, Chicago, v. 51, n. 3, p. 911-962, 2002.

GOMES, Mércio Pereira. 1977. The ethnic survival of the Tenetehara of Maranhão, Brazil. Dissertation (Doctor of Philosophy) - University of Florida, Gainesville, 1977.

GOODWIN, Michele. The free-market approach to adoption: the value of a baby. Boston College Third World Law Journal, Boston, v. 26, n. 1, p. 61-79, 2006.

GRAFF, Nicole Bartner. Intercountry adoption and the convention on the rights of the child: can the free market in children be controlled? Syracuse Journal of International Law and Commerce, Syracuse, v. 27, n. 2, p. 405-430, 2000.

HAUSS, Gisela; ZIEGLER, Béatrice. City welfare in the sway of eugenics: a Swiss case study. British Journal of Social Work, Oxford, v. 38, n. 4, p. 751-770, June 2008. 
HOLLINGER, Joan Heifetz. Beyond the best interests of the tribe: the Indian child welfare act and the adoption of Indian children. University of Detroit Law Review, Detroit, v. 66, p. 451-501, 1988.

HUONKER, Thomas. Fahrendes volk, verfolgt und verfemt: Jenische lebensläufe. Zürich: Limmat, 1987.

HUONKER, Thomas. La persécution des Yéniches en Suisse: retrait systématique des enfants, internement, entraves au mariage et stérilisation forcée. Disponível em: http://www. romasintigenocide.eu/media/france/f-g-yeniches.

HÜTTENMOSER, Marco; ZATTI, Kathrin B. Pflegekinder. In: HISTORISCHES Lexikon der Schweiz. Bern: Schweizerischen Akademie der Geistes- und Sozialwissenschaften, 2010. Disponível em: https://hls-dhs-dss.ch/de/articles/016590/2010-09-28/.

INSIDE China’s ‘thought transformation' camps. BBC News, 13 July 2019.

INTERNATIONAL COURT OF JUSTICE. Case concerning application of the Convention on the Prevention and Punishment of the Crime of Genocide. Bosnia and Herzegovina v. Serbia and Montenegro. Judgment of 26 February 2007, 2007. Disponível em: https://www.icj-cij.org/files/ case-related/91/091-20070226-JUD-01-00-EN.pdf.

INTERNATIONAL CRIMINAL COURT. Elements of crimes. Den Haag, 2011. Disponível em: $\quad$ https://www.icc-cpi.int/nr/rdonlyres/336923d8-a6ad-40ec-ad7b-45bf9de73d56/0/ elementsofcrimeseng.pdf.

IRELAND. Mother and Baby Homes Commission of Investigation. List of Institutions under investigation. Disponível em: http://www.mbhcoi.ie/MBH.nsf/page/List\%20of\%20Institutions\%20 under\%20Investigation-en.

IRELAND. Statutory Instrument 57 of 2015. Commission of Investigation (Mother and Baby Homes and Certain Related Matters) Order 2015. Stationery Office. Disponível em: http://www. irishstatutebook.ie/eli/2015/si/57/made/en/pdf

JÖRGER, Josef. Psychiatrische familiengeschichten. Berlin: Springer, 1919.

KING, Shani. Challenging monohumanism: an argument for changing the way we think about intercountry adoption. Michigan Journal for International Law, Ann Arbor, v. 30, n. 2, p. 413-470, 2009.

KIPLING, Rudyard. The jungle book. New York: Century, 1910.

KREß, Claus. The crime of genocide under international law. International Criminal Law Review, Leiden, v. 6, n. 4, p. 461-502, 2006.

LEIMGRUBER, Walter; SABLONIER, Roger; MEIER, Thomas. Das hilfswerk für die kinder der landstrasse: historische studie aufgrund der akten der Stiftung Pro Juventute im schweizerischen bundesarchiv. Bern: Schweizerisches Bundesarchiv, 1998. 
LEITE, Serafim. Cartas dos primeiros jesuitas do Brasil. São Paulo: Comissão do IV Centenário da Cidade de São Paulo, 1954. t. 2.

LEMKIN, Raphael. Axis rule in occupied europe. Washington: Carnegie Endowment, 1944.

LEMKIN, Raphael. V Conferencia internacional para la unificación del derecho penal. Madrid: Imprenta Galo Saez, 1933. p. 1-19.

LEMKIN; Raphael; FRIEZE, Donna-Lee (ed.). Totally unofficial: the autobiography of Raphael Lemkin. New Haven: Yale University Press, 2013.

LEMOS, Vinícius. 'Adoção na passarela': o desfile de adolescentes que gerou revolta nas redes. $B B C$ News Brasil, 22 maio de 2019. Disponível em: https://www.bbc.com/portuguese/geral-48374660.

LEO Varadkar: adoption registrations 'a dark chapter'. BBC News, 30 May 2018. Disponível em: https://www.bbc.com/news/world-europe-44305936.

MACDONALD, David B.; HUDSON, Graham. The genocide question and the Indian residential schools in Canada. Cambridge: Cambridge University Press. Canadian Journal of Political Science, v. 45, n. 2, p. 427-449, June 2012.

MEZZETTI, Enrico. I crimini di genocidio. In: LATTANZI, Giorgio; MONETTI, Vito. La Corte penale internazionale: organi, competenza, reati, processo. Milano: Giuffrè, 2006. p. 559-597.

MILLER, Jim R. Residential schools in Canada. The Canadian Encyclopedia, Oct. 2012. Disponível em: https://www.thecanadianencyclopedia.ca/en/article/residential-schools.

MOTTIER, Véronique. Eugenics, politics and the state: social democracy and the Swiss 'gardening state'. Studies in History and Philosophy of Science Part C: Studies in History and Philosophy of Biological and Biomedical Sciences, Amsterdam, v. 39, n. 2, p. 263-269, June 2008.

NIESSEN, Shuana. Shattering the silence: the hidden history of Indian residential schools in Saskatchewan. Regina: University of Regina, 2017.

O’REILLY, Alison. A mass grave of 800 babies. 25 May 2014. Disponível em: https://www.abc.net. au/mediawatch/transcripts/1422_irishmailtuam.pdf.

O'SULLIVAN, Eoin; O'DONNEL, Ian. Coercive confinement in the Republic of Ireland: the waning of a culture of control. Punishment \& Society, London, v. 9, n. 1, p. 27-48, Jan. 2007.

ONUMA, Yasuaki. Direito internacional em perspectiva transcivilizacional: questionamento da estrutura cognitiva predominante no emergente mundo multipolar e multicivilizacional do século XXI. Organizadores da tradução: Masato Ninomiya e Paulo Borba Casella. Belo Horizonte: Arraes. 2017.

PAIVA, José Maria de. Transmitindo cultura: a catequização dos índios do Brasil, 1549-1600. Curitiba: PUCPR. Revista Diálogo Educacional, Curitiba, v. 1, n. 2, jul./dez. 2000. 
PALMISTE, Claire. From the Indian adoption project to the Indian child welfare act: the resistance of Native American communities. Pointe-à-Pitre: Université des Antilles, 2011.

PRO JUVENTUTE. Foire aux questions. Disponível em: https://www.projuventute.ch/fileadmin/ fileablage/ueber_uns/Kinder_der_Landstrasse/KiLa_Fragen_Antworten_f.pdf.

PRO JUVENTUTE. Histoire de la fondation. Disponível em: https://www.projuventute.ch/ Histoire.69.0.html?\&L=1.

REIS, Lucas. No Pará, casal faz anúncio em jornal para 'adotar' babá. Folha de S.Paulo, São Paulo. 8 maio 2015. Disponível em: https://www1.folha.uol.com.br/cotidiano/2015/05/1626311-no-paracasal-faz-anuncio-em-jornal-para-adotar-baba.shtml.

ROCHA, Vanessa Anelise F. da. A conversão do gentio: franciscanos e indígenas nos espaços dos aldeamentos na capitania de Pernambuco entre os séculos XVII e XVIII. In: ENCONTRO REGIONAL DE HISTÓRIA, 16., 2014, Rio de Janeiro. Anais [...]. Rio de Janeiro: ANPUH-RIO, 2014. Disponível em: http://www.encontro2014.rj.anpuh.org/resources/anais/28/1400292060_ ARQUIVO_Artigo_Aconversaodogentio_ANPUHRIO.pdf.

RODRIGUES, Aryon Dall'Igna. Línguas Brasileiras: para o conhecimento das línguas indígenas. São Paulo: Loyola, 1986.

RODRIGUES, Lucicleide Araújo; DIAS, Kétsia Ferreira Viana Bezerra; LIMA, Valéria de Araújo. A educação indígena no período colonial (1500-1822). In: CONGRESSO NACIONAL DE PRÁTICAS EDUCATIVAS, 1., 2017, Campina Grande. Anais [...]. Campina Grande: Realize Eventos, 2017. Disponível em: https:/www.editorarealize.com.br/revistas/coprecis/trabalhos/ TRABALHO_EV077_MD1_SA9_ID237_13092017223047.pdf.

ROME STATUTE, 2002. Disponível em: https://www.icc-cpi.int/resource-library/documents/rseng.pdf.

SANTS, H. J. Genealogical bewilderment in children with substitutive parents. British Journal of Medical Psychology, London, v. 37, n. 2, p. 133-142, June, 1964.

SCHABAS, William A. Article 6. Genocide. In: TRIFFTERER, Otto; AMBOS, Kai. The Rome Statute of the International Criminal Court: a commentary. 3. ed. München: $\mathrm{CH}$ Beck; Hart; Nomos, 2015. p. 127-143.

SCHABAS, William A. Genocide in international law: the crimes of crimes. 2. ed. Cambridge: Cambridge University Press, July 2009.

SCHWEIZERISCHE EIDGENOSSENSCHAFT. Bundesgesetz über die aufarbeitung der fürsorgerischen zwangsmassnahmen und fremdplatzierungen vor 1981. AS 2017, p. 753. Disponível em: https://www.admin.ch/opc/de/official-compilation/2017/753.pdf. 
SCHWEIZERISCHE EIDGENOSSENSCHAFT. Bundesgesetz über die rehabilitierung administrativ versorgter Menschen. März 2014. p. 2.293. Disponível em: https://www.admin.ch/ opc/de/official-compilation/2014/2293.pdf.

SEPARATION at the border: children wait in cages at south Texas warehouse. The Guardian, London, 17 June 2018. Disponível em: https://www.theguardian.com/us-news/2018/jun/17/ separation-border-children-cages-south-texas-warehouse-holding-facility.

SHARP, Alastair. Six things you need to know about Justin Trudeau's apology to Inuit communities. National Observer, Vancouver, March 2019. Disponível em: https://www.nationalobserver. com/2019/03/12/analysis/six-things-you-need-know-about-justin-trudeaus-apology-inuitcommunities.

SHORT, Damien. Cultural genocide and indigenous peoples: a sociological approach. International Journal of Human Rights, London, v. 14, n. 6, p. 833-848, 2010.

SPYRI, Johanna. Heidis Lehr- und wanderjahre: eine geschichte für kinder und auch für solche, welche die kinder lieb haben. Gotha: Perthes, 1880.

TIMELINE of residential schools, the Truth and Reconciliation Commission, A. CBC News, May 2008. Disponível em: https://www.cbc.ca/news/canada/a-timeline-of-residential-schools-the-truthand-reconciliation-commission-1.724434.

UNITED NATIONS. Convention on the prevention and punishment of the crime of genocide, 1948. Disponível em: un.org/en/genocideprevention/documents/atrocity-crimes/Doc.1_Convention\%20 on $\% 20$ the $\% 20$ Prevention $\% 20$ and $\% 20$ Punishment $\% 20$ of $\% 20$ the $\% 20$ Crime $\% 20$ of $\% 20$ Genocide. pdf.

UNITED NATIONS. Draft code of crimes against the peace and security of mankind. In:

Report of the International Law Commission on the work of its forty-third session, 29 April-19 July 1991. v. 2. p. 79-107. Disponível em: http://legal.un.org/ilc/documentation/english/reports/a_46_10. pdf.

WILL, Karhen Lola Porfírio. Genocídio indígena no Brasil. Dissertação (Mestrado em Ciências Jurídico-Políticas) - Faculdade de Direito, Universidade de Coimbra, Coimbra, 2014. 